\title{
KOREKSI ATAS : PERSPEKTIF “ONTOLOGI" DALAM FILSAFAT ILMU (Telaah Atas Buku Filsafat Ilmu Tulisan Jujun S. Suriasumantri)
}

Drs. Abd. Ghafir, MA.

\begin{abstract}
Abstraks
Setiap disiplin Ilmu Pengetahuan memiliki ruang lingkup pembahasan atas dasar epistemologi yang menjadi acuan didalam pembahasannya. Sesuatu epistemologi tertentu mungkin saja dapat menjadi acuan dari beberapa ilmu pengetahuan atau mungkin saja berbeda epistemologinya. . Akan tetapi pesan yang akan disampaikan oleh suatu ilmu pengetahuan tertentu, mestinya dapat berbeda-beda, setidaknya dalam hal spesifikasi dan ketentuan-ketentuan yang berlaku dalam ilmu pengetahuan tersebut, termasuk dalam hal terminologi-terminologi yang dipergunakan. Apabila hal ini diabaikan, maka akan menimbulkan kerancuan pemahaman dan pada gilirannya pesan yang akan disampaikan disiplin ilmu tersebut tidak mencapai sasaran, bahkan justru menimbulkan persoalan. Lebih-lebih antara Filsafat dan Ilmu Pengetahuan secara tegas terdapat perbedaan epistemologi yang signifikan. Kalau Filsafat berangkat dari semangat berfikir kontemplatif yang tidak terlegitimasi dengan involusi disiplin apapun, dalam wacana yang bebas dan tidak terdependensi. Sementara Ilmu Pengetahuan berangkat dari kaidah-kaidah tertentu, bahkan terdependensi pada suatu disiplin tertentu. Hal ini berarti bahwa berbicara tentang Filsafat harus lepas dari konteks disiplin, spesifikasi dan legitimasi apapun. Tulisan ini mencoba memaparkan beberapa istilah yang berlaku dalam Filsafat Ilmu yang semestinya tidak perlu terjadi dan sah-sah saja untuk dikoreksi, kalau tidak boleh diartikan meluruskan pengertian. Yakni penggunaan istilah "Filsafat" yang dikwalifikasikan dengan istilah "Ilmu" dan istilah "ontologi" atas buku Filsafat Ilmu (Sebuah Pengantar Populer), karya Jujun S. Suriasumantri yang dipublikasikan oleh: Pustaka Sinar Harapan, Jakarta, 1996.
\end{abstract}

Kata kunci: ilmu, filsafat, ontologi dan metafisika.

\section{Abstract}


Each discipline of Sciences has a scope of discussion on the basis of epistemology which is the reference in the discussion. Something particular epistemology may be a reference from some science or may be different epistemology. . However, the message to be conveyed by a particular science, should be different, at least in terms of the specifications and provisions applicable in that science, including in terms of the terminology used. If this is ignored, it will cause confusion of understanding and in turn the message to be delivered discipline does not reach the target, even it raises the problem. Moreover, between Philosophy and Science, there is clearly a significant epistemological difference. If Philosophy departs from the spirit of contemplative thinking that is not legitimated with the involution of any discipline, in a free and underserved discourse. While Science departs from certain rules, even depended on a particular discipline. This means that speaking of Philosophy must be independent of any discipline, specification and legitimacy context. This paper attempts to describe some of the terms applicable in Philosophy of Sciences which should not have happened and is legitimate to be corrected, otherwise it can be interpreted to straighten understanding. Namely the use of the term "Philosophy" which is qualified by the term "Science" and the term "ontology" on the book Philosophy of Science (A Popular Introduction), by Jujun S. Suriasumantri published by: Pustaka Sinar Harapan, Jakarta, 1996.

Keywords: science, philosophy, ontology and metaphysics.

\section{A. Pendahuluan}

Ada perbedaan yang tegas antara Filsafat dan Ilmu, Filsafat berangkat dari semangat berfikir kontemplatif yang tidak terlegitimasi dengan involusi disiplin apapun, dalam wacana yang bebas dan tidak terdependensi. Semantara Ilmu Pengetahuan berangkat dari kaidah-kaidah tertentu, bahkan terdependensi pada disiplin tertentu. Hal ini berarti bahwa berbicara tentang Filsafat harus lepas dari konteks disiplin, spesifikasi dan legitimasi apapun.

Dengan demikian apabila persepektif dicoba dipaksakan untuk berbicara filsafat yang dikaitkan dengan Ilmu (Baca; Filsafat Ilmu), maka menjadi rancu dan absurd. Sebab, kajian dan pembicaraan Filsafat sudah keluar dari independensi dimaksud diatas.

Pada tingkat terminologi: penggunaan istilah Filsafat Ilmu saja tampak jelas terjadi kerancuan penggunaan istilah Filsafat yang dikualifikasikan dengan terminologi Ilmu. Sehingga Filsafat terbelenggu oleh kaidah-kaidah yang berlaku pada Ilmu Pengetahuan. Oleh karena itu wajar apabila kemudian terjadi kerancuan yang lebih dalam pada tingkat pengunaan neologisme dan terminologi ketika harus berbicara tentang epistemologi "ontologi", bahkan kerancuan pada pengunaan neologisme-neologisme yang dipakai dalam buku Filsafat Ilmu pada umumnya.

Kerancuan terminologi "ontologi" yang dipergunakan dalam konteks Filsafat Ilmu ini akhirnya terjebak pada terminologi "ontic". Dimana kedua-kedua terminologi itu samasekali berbeda, walaupun masih dalam kerangka berbicara tentang "ada".

Kendati kajian ini merupakan koreksi atas kedua-dua terminologi tersebut diatas mengenai 
penggunaan istilah Filsafat Ilmu dan Ontologi namun kajian ini menyatakan respect atas spekulatifnya menggunakan istilah-istilah tersebut, walaupun penulisan tersebut meragukan : benarkah penggunaan istilah Filsafat Ilmu dengan seluruh terminologi yang berlaku didalamnya sudah merupakan otoritas yang diakui oleh berbagai pihak, atau sekedar pemaparan experimental yang bersifat spekulatif, agar kedepan diharapkan dapat koreksi dan penyempurnaan sehingga secara sah epistemologi ini mendapat legitimasi "Ke-Ilmu-an" atau "Ke-Filsafat-an"?

Kajian ini akan menitikberatkan pada penggunaan terminologi "ontologi" yang rancu yang berlaku dalam disiplin "Filsafat Ilmu", meskipun penggunaan istilah "Filsafat Ilmu" itu sendiri sebenarnya perlu dikoreksi. Hal ini untuk membatasi permasalahan yang dikaji. Namun negasi terhadap penggunaan istilah ontologi dalam hal ini, secara implisit sebenarnya berarti pula negasi terhadap penggunaan istilah "Filsafat Ilmu" itu sendiri.

\section{B. Perbedaan Ontic Dan Ontologi}

Mencermati perbedaan perspektif "ontic" dan "ontologi" dalam konteks ini merupakan keharusan, untuk menelaah kerancuan yang terjadi dalam penggunaan terminologi "ontologi" dalam disiplin "Filsafat Ilmu".

Terminologi ontic dan ontologi diintrodusir oleh kalangan Filsuf Existensialisme pada umumnya. Martin Heidegger salah seorang Filsuf Besar Existensialisme menjelaskan makna ontic sebagai: "... As ontic term, "world signifiens the totality of be-ings which can be present within the universe". ${ }^{1}$

Yakni suatu terms untuk menyatakan totalitas be-ings (pakai tanda penghubung -) yang berarti ada-an / benda, selain ada-manusia yang ada dalam alam semesta). Sedangkan "Ontologi" is the name for the explisit theoretical inquiry into the meaning of the (being of) entries" Yakni merupakan teori penyelidikan yang mengarah kepada makna being yang sebenarnya, makna being (tanpa tanda penghubung - ) dari be-ings, (ada dari ada-an) secara umum.

Pengertian being (ada) dalam konteks pendekatan ontologis sering diartikan sebagai adamanusia, seperti pada pernyataan:

"Thus, only by a profound analysis of man's being of Dasein can we arrive at an insight in to the being the be-ings. In this sense an analysis of our human existence constitutes a necessary condition for a genuine ontology". ${ }^{3}$

Dari pernyataan tersebut menunjukkan bahwa hanya dengan suatu analisa yang mendalam tentang ada-manusia (Martin Heidegger menyebutnya Dasein), maka dapat sampai kepada pengamatan tentang "ada" dari ada-an - ada-an. Hal ini berarti bahwa analisa yang dilakukan terhadap eksistensi manusia merupakan kondisi yang diperlukan untuk perspektif ontologi yang murni.

1 Joseph Kockelmans, Martin Heidegger, A First Introduction to his philosophy, Duquesne University Press, USA, 1965 p. 28.

2 Richard Schmitt, Martin Heidegger on Being Human, an Introduction to Sein Und Zeit. Random House. New York, 1969 p. 18

3 Joseph Kockelmans, Martin Heidegger, A First Introduction to his philosophy, Duquesne University Press, USA, 1965, p. 14. 
Analisa terhadap pernyataan-pernyataan tersebut diatas, menunjukkan terdapat semacam keidentikan antara eksistensi manusia dan ontologi. Bahkan kajian ini mencoba menyatakan bahwa ontologi dalam stadium lebih universal dan transendental, bisa jadi ontologi juga merupakan epistemologi tentang ada-nya $A d a$, ( $A d a$, dengan inisial huruf kapital A besar). Ilustrasi religius versi Islam, barangkali yang dimaksud dengan transendensi itu ialah Ada-nya Allah, atau secara universal adalah Tuhan.

Terlepas dari interpretasi tersebut diatas, epistemologi ontologis terhadap ada-nya ada, merupakan keidentikan juga, antara $A d a$ (yang transenden) dan Ontologi, sebagaimana yang berlaku pada antara Ada dan Ontologi.

Dalam tradisi Filsafat Eksistensialisme, pernyataan yang disebut pertama diilustrasikan sebagai:

"Yet analytical philosophers in particular are highly suspicious of any inquiry into Being (especially when this is spalled with a capital letter!). Their nomanilism leads them to suppose that anyone engaging in such an inquiry (ontology has) has fallen into the error of supposing that because we have a noun "Being" in the lan uage, there must be something corresponding, to the word, out there in world".

Para filsuf masih menaruh kecurigaan yang cukup tinggi terhadap analisa pernyataan tentang "Being" (Ada). Bahkan aliran Normalisme mencoba membimbing mereka yang terikat pada analisa pernyataan tentang Being (Ontologi), telah terjebak pada kesalahan tentang analisa itu sendiri. Hal ini disebabkan karena, secara lughowiyah Being itu hanya bermakna Ada. (kt. Benda). Sehingga pernyataan tentang Being (inisial B besar), dapat dipakai untuk menyatakan keseluruhan tentang $A d a$ pada umumnya. Analisa tersebut diatas mengindikasikan bahwa ontologi dalam konteks ini dipakai untuk keperluan analisa terhadap Being.

Perbedaan perspektif onticdan ontologi dipertegas Heidegger dalam bukunya Sein und Zeit (1927) bahwa:

“... the terms 'ontisch' ('ontical') and 'ontologisch' ('ontological') are not explicitly defined, their meanings will emerge rather clearly. Ontological inquiry is concerned primarily with Being; ontical inquiry is concerned primarily with entities and the facts about them"s

Persepektif ontic dan ontologic adalah dua terminologi yang jelas berbeda makna. Kalau ontology ialah suatu penyelidikan yang berkaitan dengan being, sedangkan ontic seseutu yang berkaitan dengan the facts (benda-benda/ada-an-ada-an).

Resume dari kajian tentang ontic dan ontologi tersebut diatas, dapat disimpulkan sebagai berikut:

Pertama, bahwa term ontik merupakan pernyataan perspektif atas ada-an, (benda, things), yang menjadi obyek kajian ilmu pengetahuan, pertanyaan, penyelidikan yang bersifat terbatas

4 John Macquarrie, Martin Heidegger, Lutterworth Press, London 1968. p. 4.

5 Heidegger, Martin, Sein und Zeit, Translated by Macquarrie, John \& Edward Robinson, Being and Time, (SanFrancisco: Harper \& Row Publishers, Incorporated, 1962.). p. 31 
dan dependen.

Kedua, bahwa term ontologi dipakai untuk keperluan pertanyaan dan penyelidikan yang mendalam yang berkaitan dengan ada-nya manusia dan Ada yang transenden.

\section{Perbedaan Ontologi Dan Metafisika}

Agar kajian ini lebih terfokus, maka perlu dipaparkan juga perbedaan antara ontologi dan metafisika. Secara sederhana dapat ditegaskan lagi bahwa ontologi ialah epistemologi yang menunjukkan arti kepada pemikiran yang memusatkan perhatian kepada struktur dasar yang $a d a$, lepas dari segala legitimasi apapun, lepas dari dapat atau tidak diamati dan atau dianalisa oleh ada-manusia.

Sedangkan metafisika ialah pemikiran mendalam yang memusatkan perhatiannya kepada akar terdalam yang mendasari segala yang ada dan atau dibalik (meta)yang ada itu sendiri, maka disebut metafisika

Dengan demikian jika ontologi berangkat dari analisa struktur dasar dari ada, maka metafisika berangkat dari ada yang terlegitimasi, yakni mencari jawaban tentang yang ada melalui jalan pikiran kausalitas. Penggunaan terminologi metafisika ini pada umumnya dipakai dalam ruang lingkup tradisi kajian filosofis. Contoh: kursi dibuat oleh manusia, manusia diciptakan oleh Tuhan. Sampai pada Tuhan analisa berhenti, berhenti pada Tuhan inilah pikiran menjadi terlegitimasi, terbatas dan dependen.

Filsafat metafisika pada umumnya diwakili oleh aliran "materialisme" dan "idelisme". Aliran "materialisme" mengandaikan manusia hanyalah sekedar materi, , yang dicetuskan kali oleh Leucippus (440 SM) seorang filsus periode Filsafat Yunani Purba ${ }^{6} 6$ yang berkeyakinan bahwa segala sesuatu termasuk badan jiwa dan roh manusia terdiri dari atom (materi) yang dikuasai oleh tatalaksana mekanistis.7 Sedangkan "idealisme" berpendapat bahwa yang-ada hanyalah sekedar idea atau bentuk yang tergambar dalam pikiran semata-mata, ia tidak hadir dalam sesuatu wujud kebendaan. Kebendaan yang riil, yang dapat diserap oleh panca indera hanyalah semu belaka, berubah-ubah dan tidak sempurna. Dunia yang riil hanyalah bayangan dari idea yang ada dalam fikiran. ${ }^{8}$

\section{Perspektif Ontic Sebagai Tradisi Pemikiran Filsafat Metafisik}

Para Filsuf sejak mulai Alam Pikiran Yunani Purba sampai Alam Pikiran Dewasa ini telah berusaha mencari jawaban tentang ada. Namun pemikiran filsafat yang lahir sebelum aliran Eksistensialisme - yakni dari Filsafat Yunani Purba sampai dengan Filsafat Modern yang

6 Campbell, Keith, "Materialism", The Encyclopedia of Philisophy, V, (New York : Macmillan Co. Inc. \& The Free Press, 1974). P. 180

7 Harahap, Ds. FKN., Tokoh-tokoh Dunia dalam Lapangan Berfikir, (Bandung : PT Karya Nusantara, 1978). p. 113

8 Acton, HB., "Idealism", The Encyclopedia of Philosophy III, (New York : Maccmillan Publishing Co. Inc. \&The Free Press, 1973). P. 111 
puncaknya direpresentasikan Friedrich Wilhem Nietzche (1844 - 1900) - selalu terjebak pada pemikiran metafisik (berhenti pada dibalik yang ada). Disebut metafisik, karena pada periode tersebut pemikiran filsafat mengandaikan tentang Ada diasal-usulkan kepada sesuatu. Sehingga apabila sesuatu itu sampai pada akhir matarantainya, pemikiran berhenti pada suatu ketentuan. Kemudian sesuatu yang terakhir itu disebutnya hakekat, sebagai esensi. Perspektif tentang ada, selanjutnya diserahkan kepada apa yang terdapat di belakang hakekat itu (metafisika).

Semangat berpikir yang mengandaikan ada sebagai sesuatu yang pada akhirnya sampai pada sesuatu instansi tertentu, inilah yang disebut "ontic". Semangat berpikir ontic selalu menggunakan hukum kausal-mekanis, pembuktian kosmologis, instansi akhir dan hakekat, dan hal ini merupakan prinsip yang digunakan dalam sains, ilmu pengetahuan, maupun teknologi. Ada akhirnya diandaikan sebagai atom (Materialisme), Ada akhirnya idea (Idealisme), ada akhirnya ciptaan Tuhan. Oleh karena itu ilmu pengetahuan dan teknologi adalah pemikiran yang bergerak dilingkungan ontic. Artinya epistemologi ilmu pengetahuan berangkat bukan dari pemikiran filsafat yang bergerak dilingkungan perspektif ontologi.

\section{E. Ontologi Tidak Berbicara Perspektif: Hakekat yang Dikaji}

Analisa diatas telah menjelaskan bahwa hakekat, esensi adalah ruang lingkup filsafat metafisika. Hal ini berarti bahwa epistemogi yang berlaku pada ilmu pengetahuan (tentunya termasuk Filsafat Ilmu) dan teknologi bukanlah objek kajian yang berangkat dari ontologi. Karena ilmu pengetahuan dan teknologi berangkat dari pemikiran metafisika dan berakhir pada hakekat, esensi. Sebuah misal : kajian Ilmu Fisika akan terbentur, berhenti ketika berbicara tentang atom. Atom akhirnya diserahkan pada epistemologi metafisik (berhenti, kajiannya dibalik/dibelakang atom itu sendiri, ke-apaannya dan atau ke-siapa-annya, hakikinya yang tidak pernah terjawab).

Apabila kajian ini mengkritisi (kalau tidak boleh disebut mengkoreksi), secara sample, ambil saja sebuah kajian "ontologi” yang diintrodusir oleh Jujun S. Suriasumantri dalam titelnya "Filsafat Ilmu Sebuah Pengantar Populer" misalnya, maka terdapat banyak kerancuan.

Jujun memulai motto pada halaman-halaman awal bukunya sudah menunjukkan kerancuannya. Seperti: "Der Herr gott wurfelt nicht" (Tuhan tidak melempar dadu) ${ }^{9}$. Mufradat Tuhan (Ada) dihadirkan begitu saja tanpa harus dipertanyakan. Mestinya jika dia bermaksud berbicara dalam kerangka ingin menggambarkan buku tersebut bernuansa refleksi filosofis, maka seharus berangkat dari sebuah pertanyaan tentang keberadaan Ada (Tuhan) terlebih dahulu, bukan tiba-tiba Tuhan Ada, kemudian melempar dadu.

Kalau kajian ini boleh mengilustrasikan motto yang lebih sesuai mestinya kalimat pertanyaannya kira-kira berbunyi "Warum gibt es etwas, und nicht vielmehr nichts"? Ada bukan ketiadaan?). Artinya muqaddimah kubra dalam kalimat tersebut harus dipertanyaakan terlebih dahulu keberadaannnya, sebelum sampai ke tingkat natijah (kesimpulan) setelah itu baru kemudian diketengahkan muqaddimah sughranya. Pertanyaan tersebut sesuai dengan

9 Jujun S. Suriasumantri, Filsafat Ilmu Sebuah Pengantar Populer, Pustaka Sinar Harapan, Jakarta, 1996, p. 61. 10 FX Muji Sutrisno, "Phenomena dan Manusia”, Majalah Driyakarya, No. 4 Th. V th.p.. 96. 
makna ontologis yang direpresentasikan dalam buku tersebut.

Contoh sederhana misalnya : pada BAB III Ontologi: Hakekat apa yang dikaji. ${ }^{11}$ Dalam kajian ini perspektif ontologi dipahami sebagai hakekat. Ini rancu, sebab hakekat itu bukan wilayah kajian ontologi. Akan tetapi wilayah kajian metafisik. Kajian kritis selanjutnya berlaku juga bagi banyak statemen yang diintrodusirnya - sengaja untuk tidak secara satu persatu mengkritisi analisa tersebut, hal ini tentu karena mengingat singkatnya kajian ini - baik terhadap tema maupun substansi bahasannya. Namun beberapa cuplikan dari beberapa tema tersebut berikut ini, cukup representatif, bahwa kajian-kajiannya menyimpang jauh dari wilayah ontologi. Sebagaimana berikut ini secara tematis dapat dilihat pada BAB III yang memaparkan “ontologi” tersebut, yang digelar dalam lima tema, yaitu:

Metafisik, 2. Asumsi, 3. Peluang, 4. Beberapa Asumsi dalam Ilmu, dan, 5. batas-batas penjelajahan Ilmu. $^{12}$

Apabila dianalisa, semua kajian tersebut diatas, sama sekali diluar batas-batas kajian wilayah ontologi.

Ad. 1. Metafisik, jelas-jelas berbeda dengan ontologi. Dalam hal ini Jujun justru memasukkannya menjadi bagian dari ontologi.

Ad. 2.Asumsi;

"Jadi marilah kita asumsikan saja bahwa hukum yang mengatur berbagai kejadian itu memang ada, sebab tanpa asumsi ini maka pembicaraan kita semuanya lantas sia-sia, tukas teoritikus Filsafat Ilmu"13

Epistemologi ontologis tidak pernah berangkat dari perspektif “ $a d a$ ” yang sebelumnya telah diasumsikan, dalam epistemologi ontologi, "add" memiliki karaktersistik eksisitensi medahului essensi, artinya bukan sebaliknya, yakni esensi atau hakekat yang diasumsikan atau dilegitimasikan sehingga menunjukkan kesan esensi mendahului eksistensi. Asumsi adalah wilayah kajian matafiska. Demikian juga istilah hukum, penyelidikan ontologis samasekali lepas dari ranah hukum yang melegitimasikannya atas sesuatu apapun. Hukum merupakan determinasi terhadap esensialitas $a d a$, karena didalamnya terdapat legitimasi dan batas-batas, dimana keduanya merupakan hal-hal yang bertentangan dengan prinsip ontologi.

Masih banyak lagi terminologo-terminologi yang dipergunakan Jujun untuk mengekspresikan ontologi namun terjebak pada konsep metafisik, khususnya yang termaktub pada halaman $72 \mathrm{~s} / \mathrm{d} 81$ buku tersebut.

Demikian beberapa kajian singkat yang bersifat korektif atas penggunaan epistemologi ontologi dalam ruang lingkup Filsafat Ilmu. Walaupun mengambil beberapa sampel pernyataan,

11 Jujun S. Suriasumantri, Filsafat Ilmu Sebuah Pengantar Populer, Pustaka Sinar Harapan, Jakarta, 1996, p.

12 Jujun S. Suriasumantri, Filsafat Ilmu Sebuah Pengantar Populer, Pustaka Sinar Harapan, Jakarta, 1996, p.

61

13Jujun S. Suriasumantri, Filsafat Ilmu Sebuah Pengantar Populer, Pustaka Sinar Harapan, Jakarta, 1996, p . 75. 
namun cukup representatif. Untuk mengetahui lebih dalam, dapat mengkaji kerancuan penggunaan istilah-istilah itu pada titel yang ditulis ole Jujun S. Suriasumantri tersebut diatas.

\section{F. Kesimpulan}

1. Ontic adalah nama bagi analisa mendalam terhadap bendaatau ada-an yang ada di alam semesta. Secara umum untuk keperluan analisa filsafat Metafisika, secara khusus untuk keperluan analisa bagi Ilmu Pengetahuan dan Teknologi.

2. Ontologi adalah istilah bagi analisa mendalam terhadap ada (human existent) dan Ada (Transcendental Being) yang lepas dari segala legitimasi, dipergunakan dalam kajian filsafat ontologi

3. Ontic adalah nama dari ciri epistemologi metafisik, yang analisanya berangkat dari sesuatu yang terdependensi, dan berakhir pada sesuatu instansi yang disebut essensi atau hakikat, dipergunakan dalam tradisi filsafat metafisika.

4. Kekeliruan penggunaan terminologi ontologi untuk keperluan analisa dan penyelidikan Ilmu Pengetahuan dan Teknologi, berakibat rancaunya arah kajian.

\section{G. Saran Dan Usul}

1. Disarankan mempertimbangkan kembali penggunaan terminologi ontologi untuk keperluan analisa dan Penyelidikan Ilmu Pengetahuan dan Teknologi.

2. Diusulkan untuk meninjau kembali otoritas disiplin Filsafat Ilmu, kalau tidak boleh mata kuliah Filsafat Ilmu tersebut disempurnakan dengan istilah yang sesuai untuk menunjuk makna bagi Filsafat Ilmu.

\section{H. Penutup}

Koreksi ini dipaparkan, semata-mata bermaksud mempertegas dan membedakan istilahistilah yang berlaku dalam ruang lingkup masing-masing disiplin pengetahuan agar tidak terjadi kesalahmengertian. Ilmu Pengetahuan memiliki ruang lingkup kajian yang tentunya atas dasar epistemologi yang berlaku didalamnya demikian halnya dengan filsafat. Oleh karena itu istilahistlah yang dipergunakan, sudah sewajarnya sejauh masih dalam kerangka yang mencerminkan keterkaitan antara ilmu pengetahuan itu sendiri dengan istilah-istilah yang berlaku.

\section{Bibliografi}


Acton, HB., "Idealism", The Encyclopedia of Philosophy III, (New York : Maccmillan

Publishing Co. Inc. \&The Free Press, 1973).

Campbell, Keith, "Materialism”, The Encyclopedia of Philisophy, V, (New York : Macmillan Co. Inc. \& The Free Press, 1974).

Harahap, Ds. FKN., Tokoh-tokoh Dunia dalam Lapangan Berfikir, (Bandung : PT Karya Nusantara, 1978).

Heidegger, Martin, Sein und Zeit, Translated by Macquarrie, John \& Edward Robinson, Being and Time, (SanFrancisco : Harper \& Row Publishers, Incorporated, 1962.)

Kockelmans, Joseph, Martin Heidegger, A First Introduction to his philosophy, Duquesne University Press, USA, 1965.

Macquarrie, John, Martin Heidegger, Lutterworth Press, London 1968.

Muji Sutrisno, FX, "Phenomena dan Manusia”, Majalah Driyakarya, No. 4 Th. V, tth.

Richard Schmitt, Martin Heidegger on Being Human, an Introduction to Sein Und Zeit. Random House. New York, 1969.

Suriasumantri, Jujun S., Filsafat Ilmu, Sebuah Pengantar Populer, Pustaka Sinar Harapan, Jakarta, 1996. 